\title{
La construcción socioimaginaria de la mujer en la crítica literaria periodística: resultados del estudio de la producción cultural de la revista de libros del diario El Mercurio de Santiago de Chile
}

\author{
Alberto Javier Mayorga Rojel, Luis Nitrihual Valdebenito, Macarena Herrera \\ SALAZAR, Juan Manuel FiERro Bustos* \\ luisnitrihual@gmail.com
}

(Abstracts y palabras clave al final del artículo)

Enviado: 13 de julio de 2012

Evaluado: 20 de julio de 2012

Aceptado: 2 de agosto de 2012

\section{PRESENTACIÓN DE ESTUDIO}

Si consideramos las lógicas de funcionamiento y las dinámicas de apropiación de los mensajes producidos por los medios de comunicación en el marco de sus constantes procesos de transformación tecnológica y legitimación dentro del espacio público contemporáneo, entonces es razonable sostener que los medios de comunicación son actores claves en la estructuración de esquemas mentales de interpretación y, por ende, los segmentos de consumidores de productos mediáticos de diversa índole los consideran relevantes y centrales para el desarrollo diario de sus actividades cotidianas. Es más, los medios de comunicación reconfiguran las instancias de mediación social gestionando diversos dispositivos comunicacionales y reordenando el mapa de la opinión pública, lo que incluso nos permite entender el tipo de poder que ejercen los medios de comunicación social en lo que respecta a su capacidad de configurar una o varias realidades que se visualizan, leen, escuchan o digitalizan en la actualidad.

A nuestro juicio, los medios de comunicación no sólo definen los temas que las audiencias discuten en su vivir cotidiano sino también realizan un esfuerzo por establecer un conjunto de visiones del mundo que son transmitidas y funcionan como mecanismos reguladores capaces de establecer lineamientos o plataformas informativas desde donde las audiencias puedan enarbolar sus experiencias y sentidos en torno a los múltiples acontecimientos mediáticos o fenómenos sociales del pasado, presente y futuro. De este modo, la propuesta de J.B Thompson (1998) acerca de la experiencia mediática no ayuda a comprender cómo determinados imaginarios sociales se acuñan en el discurso de los mass media y se institucionalizan sobre la

\footnotetext{
* Departamento de Lenguas, Literatura y Comunicación. Facultad de Educación, Ciencias Sociales y Humanidades.Universidad de La Frontera. Temuco. Chile.

${ }^{1}$ Estudio adscrito al programa de investigación Imaginarios Sociales, Discurso y Poder desarrollado por el Grupo de Investigación en Comunicación y Saberes Críticos; y financiado por la Dirección de Investigación de la Universidad de La Frontera, proyectos DIUFRO DI11-0006 y DIUFRO DI12-0060.
} 
base de una ausencia evidente de una cultura de lectura crítica de los medios y mediante el consenso vía consumo heterónomo de las audiencias. Por consiguiente, en este marco general sobre los medios de comunicación social, nos interesa presentar en este artículo los resultados de una investigación descriptiva acerca de la construcción socioimaginaria de la Mujer en el discurso mediático de la crítica literaria periodística ${ }^{2}$ en Chile. En este sentido, considerando la importancia que tienen los discursos periodísticos/crítica literaria producidos por los medios de comunicación social, en general y por la prensa, en particular, en la cristalización de imaginarios sociales y, a su vez, el objetivo de conocer las categorías desde las que se produce/determina la figura de la mujer, en tanto sujeto creador como objeto de la crítica; se establece la necesidad de realizar un estudio de la CLP como un tipo de discurso mediático que contribuye a la construcción y cristalización de un determinado imaginario social de la mujer y que, a lo menos desde nuestra perspectiva, resulta interesante y relevante si consideramos que: 1) la crítica literaria periodística (CLP) es un tipo de discurso poco investigado en Chile ${ }^{3}$; y 2) al buscar revelar el imaginario femenino construido en el discurso de la CLP, nos enfrentamos a un problema relevante para la investigación en el campo de la comunicación y los estudios culturales.

Finalmente, quisiéramos destacar como punto clave de nuestro trabajo que "una de las demostraciones históricas más importantes de la dominación de un imaginario social sobre otro está dada por los contenidos de las relaciones tradicionales de género (hombre/mujer)" (Baeza, 2003: 28), por tanto lo que Mercedes Arriaga (2004) define como herencia no material, es el legado de reglas sociales que determinan el comportamiento humano, lo que a su vez es reforzado por la cultura material en donde la mujer es protagonista sólo como objeto estético (en esculturas, pinturas, etc.), pero no como sujeto creador. Entonces, al considerar lo anterior, podemos asumir que el imaginario social de la mujer construido en el marco de la producción cultural vinculada al espacio de la CLP en Chile, deviene en una condición moderna del conflicto de género, donde la producción de discursos en torno al hombre/escritor y mujer/escritora podría definir y sedimentar la esfera concreta donde se lleva a cabo una lucha por la construcción de una realidad social configurada sobre la base de las intenciones de una mayoría sobre una minoría y de los elementos significativos presentes en el discurso de los agentes económicos y culturales dominantes en un país.

\footnotetext{
2 De aquí en adelante se utilizará la sigla (CLP) para referirse a la Crítica Literaria Periodística.

3 Dentro de la agenda de investigación en comunicación en Chile -demostrada de manera fundamental en investigaciones del Fondo de Desarrollo Científico y tecnológico (FONDECYT)- aparece un rasgo sugerente y relevante para nuestra investigación: no hay presencia de investigaciones que se aboquen al desarrollo del análisis del discurso de la crítica literaria ejercida en los medios de prensa. Este dato inicial -antecedente necesario de consignar- nos obliga a reflexionar en las razones de dicha ausencia, probablemente vinculada a la primacía de ciertos temas y problemas que Carlos Del Valle ha descrito en su libro Metainvestigación de la Comunicación en Chile. Pero por otro lado, lo que resulta aún más interesante, es que el tema de la literatura y el periodismo, como dos disciplinas convergentes, no ha sido lo suficientemente investigado en Chile.
} 


\section{PRECISIONES TEÓRICO-CONCEPTUALES DEL TRABAJO}

\subsection{ACERCA DEL DISCURSO DE LA PRENSA}

Desde nuestra perspectiva la producción discursiva de la prensa en el ámbito cultural juega un papel fundamental en la cristalización de imaginarios sociales de diversa índole, es decir, la prensa tiene la capacidad de reforzar o modificar las figuras de sentido que son el suministro necesario para la construcción de un conjunto socioimaginario. De esta forma, el discurso de la prensa se convierte en una estructura arquitectónicamente sólida en la medida que su base de apoyo o principio de origen se compone de una dimensión ideológica que sustenta la coherencia interna del propio sistema discursivo.

A su vez, podemos advertir que el discurso de la prensa se entiende como un dispositivo en el sentido e Foucault 4 y mediante su funcionamiento en el espacio público la élite dominante tiende a la búsqueda del control informativo en un plano inmediato, sin embargo, este control informativo adquiere una mayor complejidad sobre la base de un principio de legitimación y consenso en torno a la defensa de sus propios intereses dentro de lo que denominamos el campo de lucha de las significacio$n e s^{5}$. Estas observaciones nos llevan a reafirmar que el tipo de poder que ejerce la prensa en la sociedad contemporánea corresponde a un poder simbólico, es decir "el (poder) que procede de la actividad productiva, transmisora y receptora de formas simbólicas significativas" (Thompson, 1998: 33).

Ahora bien, una clara muestra del ejercicio del poder simbólico de la prensa corresponde a la producción de un discurso identificado como CLP y que desde sus inicios ha configurado un tipo de intervención político-cultural en el sentido que todo discurso de la prensa es un dispositivo normalizador de determinados valores culturales dominantes donde la ciudadanía se pueda reflejar o representar y, por sobre toda las cosas, donde este dispositivo sea utilizado con la finalidad de preservar la posición hegemónica ${ }^{6}$ de grupos e instituciones específicas dentro del sistema social.

4 Para Michel Foucault (1978, citado en Jäger, 2003: 71) el concepto de dispositivo se debe entender como "un conjunto decisivamente heterogéneo que abarca los discursos, instituciones, instituciones arquitectónicas, decisiones regladas, leyes, medidas administrativas, afirmaciones científicas, enseñanzas filosóficas, morales o filantrópicas, en resumen, lo que se dice y lo que no se dice". Se erige por ende, una comprensión del discurso (dispositivo) como práctica social y objeto material que, por una parte, porta en sus entrañas un conocimiento y, por otra, determina una configuración de la realidad, lo que - en palabras de Siegfried Jager (2003: 69) - "permite a los discursos ejercer un poder porque transportan un saber con el que se nutre la conciencia colectiva e individual, así como el fundamento de la acción formativa que moldea la realidad".

5 En un trabajo anterior (Mayorga, 2009: 2) hemos señalado que: "el discurso permite representar el conocimiento de algo y, por lo tanto, la acción social de construir una realidad es propia del proceso discursivo donde el significado y las prácticas significativas se realizan. Además, es factible asumir que este discurso es el reflejo de una lucha interna entre significados dominantes y dominados, entre las estrategias de construcción del sentido de los múltiples contenidos expuestos y las variadas interpretaciones que puede hacer el destinatario al tomar como elemento referencial las propias experiencias. Así, la producción y distribución del discurso permite a las instituciones mediáticas y a los estados latinoamericanos trabajar en conjunto para mantener el poder que los faculta para generar realidad y conocimiento en las audiencias.

6 Eagleton (1999) ha destacado como en la Inglaterra de fines del siglo XVIII la crítica literaria constituyó un espacio de asentamiento de los valores de la burguesía, un espacio de consenso y de libre tránsito de las opiniones. 
Para profundizar en el sentido del término poder simbólico propuesto por John. B. Thompson es necesario destacar lo siguiente: "Utilizaré el término poder simbólico para referirme a esta capacidad de intervenir en el transcurso de los acontecimientos para influir en las acciones de los otros y crear acontecimientos reales a través de los medios de producción y transmisión de las formas simbólicas" (1998: 34).

Siguiendo con lo planteado, creemos que uno de los principales objetivos del discurso de la prensa, en términos de su intervención en el ámbito cultural, es reproducir o modificar determinados imaginarios sociales preexistentes en el espacio público donde, además, las audiencias disponen de una actitud abierta al consumo acrítico del discurso de la CPL, a pesar de las resistencias que se puedan levantar desde un conjunto reducido de sujetos contrarios a las lógicas massmediáticas. Con respecto a este punto, vale pena volver a lo planteado por John B. Thompson en consideración a la instancia de consumo de bienes simbólicos por parte de las audiencias, pero particularmente al proceso de interpretación y apropiación ${ }^{7}$ de los mensajes mediáticos: "al interpretar las formas simbólicas, los individuos las incorporan dentro de su propia comprensión de sí mismos y de los otros. Las utilizan como vehículo para reflejarse a sí mismos y a los otros, como base para reflexionar sobre sí mismos, sobre los otros y sobre el mundo al cual pertenecen" (1998: 66).

En definitiva, la problematización de la construcción socioimaginaria en el marco de la producción discursiva al interior de los medios de prensa, nos permiten profundizar nuestra comprensión acerca de las estructuras de poder por medio de las cuales se promueven, por ejemplo, la cristalización de figuras de sentido en torno a la Mujer como sujeto creador en el ámbito cultural o como sujeto enraizado en la significación tradicional adscrita a las cualidades de sensibilidad, docilidad, etc. Resulta coherente, según estos supuestos teóricos que venimos planteando, que la construcción de la mujer desde una dicotomía de normalización/anormalización o tradicional/vanguardista, surja con fuerza en el marco de la producción cultural donde los medios de comunicación social se constituyen en una plataforma preciada para la puesta en escena de una diversidad de bienes simbólicos cargados de sustratos socioimaginarios.

\subsection{BREVES APUNTES EN TORNO A LOS IMAGINARIOS SOCIALES.}

Quisiéramos comenzar por la propuesta de Cornelius Castoriadis (2007: 204) respecto al término de imaginario: "Hablamos de imaginario cuando queremos hablar de algo «inventado» - ya se trate de un invento «absoluto» («una historia imaginada de cabo a rabo»), o de un deslizamiento, de un desplazamiento de sentido, en el que unos símbolos ya disponibles están investidos con otras significaciones que las suyas «normales» o canónicas $[\ldots]$ En los dos casos, se da por supuesto

\footnotetext{
7 Desde la perspectiva de John B. Thompson (1998: 66): “Apropiarse de un mensaje consiste en tomar su contenido significativo y hacerlo propio. Consiste en asimilar el mensaje e incorporarlo a la propia vida, un proceso que algunas veces tiene lugar sin esfuerzos, y otras supone un esfuerzo consciente".
} 
que lo imaginario se separa de lo real, ya sea que pretenda ponerse en su lugar (una mentira) o que no lo pretenda (una novela)".

En este sentido, la propuesta de Castoriadis acerca del concepto de imaginario se centra en la capacidad que posee lo imaginario para expresarse a través de lo simbólico, para ser visible en el entramado social y, por ende, se establece que la articulación entre significados y significantes permite una movilidad en el lenguaje y la construcción de significaciones ${ }^{8}$, o sea nos faculta como actores sociales para evocar una imagen -y más que simples imágenes- por medio de lo enunciado y llenar de sentido lo construido socialmente.

Es relevante señalar la importancia que esto representa, pues en palabras de Manuel Antonio Baeza, los imaginarios corresponden a la "institucionalización social de determinadas visiones, de determinados discursos y de determinadas prácticas con efectos sociales y, por último, hasta de determinados estilos de la acción social" (2008: 190), por lo tanto, lograr cristalizar un imaginario social es legitimar esta visión dentro de la sociedad, transformando la construcción socioimaginaria en una verdad para quienes lo internalicen/apropian.

Por su parte, Castoriadis es categórico al afirmar que: "Una vez creadas, tanto las significaciones imaginarias sociales como las instituciones se cristalizan o se solidifican, y es lo que llamo el imaginario social instituido. Este último asegura la continuidad de la sociedad, la reproducción y la repetición de las mismas formas, que de ahora en más regulan la vida de los hombres y permanecen allí hasta que un cambio histórico lento o una nueva creación masiva venga a modificarlas o a reemplazarlas radicalmente por otras formas" (Castoriadis en Baeza, 2008: 194).

Este cambio histórico o transformación al que Castoriadis se refiere surge a partir de la heteronomía, entendida como "el control que comprende no solamente la imposición de una fuerza física sobre quienes están en situación de dominados, sino también de múltiples aspectos culturales que hacen rememorar aquella conocida tesis gramsciana de la hegemonía9" (Baeza, 2003: 110). Es este tipo de influencia el que permite que cada sociedad formule las bases de su propio sistema social amparado éste en un conjunto socioimaginario legitimado y necesario para la determinación de escalas de valores diferenciadoras (lo bueno y lo malo, lo legal de lo ilegal, etc.) y funcionales en contextos específicos.

8 Para Castoriadis (2007: 536) "la significación es aquí la coparticipación de un término y de aquél al que ese término remite, poco a poco, directa o indirectamente. La significación es un haz de remisiones a partir y alrededor de un término". No obstante, obviar la existencia de un referente(s) de la palabra, subordina la palabra para ser usada - únicamente - en el sentido que le corresponde de manera directa. Así entonces, Castoriadis (2007: 540-541) afirma - de manera concluyente - que "una palabra, aun cuando se la utilice en su pretendido «sentido propio», o con su «significación cardinal», es utilizada en un sentido trópico. No existe el «sentido propio»; lo único que existe - pero siempre, e ineliminablemente, ya sea en las metáforas como en las alegorías más sutiles o más disparatadas - es la referencia identitaria, punto de una red de referencias identitarias, aprehendido él mismo en el magma de las significaciones y referido al magma de lo que es".

9 "En los textos del intelectual italiano Antonio Gramsci, la hegemonía es presentada como algo posterior a la simple coerción física sobre la cual se apoya en primer lugar la dominación; aquella se establece en el momento en que surge un aspecto "positivo" de una dirección intelectual y moral, es decir un elemento cultural que asienta un poder determinado". (Baeza, 2003: 110) 
En definitiva, es posible evidenciar que los imaginarios sociales corresponden a constructos de sentido acerca de «algo o alguien», singular o plural, individual o colectivo, público o privado, que han sido construidos socialmente a través de los dispositivos de poder existentes dentro del tejido social y que poseen un reconocimiento y legitimidad dentro del conjunto de la sociedad. Me refiero concretamente a la comprensión de los imaginarios sociales como constructos de sentido (Baeza, 2008, 2003, 2000) que poseen legitimidad para los usuarios del lenguaje y los integrantes de una sociedad, producto de un largo proceso de socialización amparado en la acción de instituir un imaginario (Baczko, 2005) compartido por aquéllos.

Como bien lo señala Manuel Antonio Baeza: "Los imaginarios sociales, al decir que son esquemas sui generis de construcción/inteligibilidad simbolizada de la realidad, se presentan frente a nosotros como amplios constructos simbólicos socializados, compartidos mediante la comunicación intersubjetiva de las personas, por lo tanto autolegitimados, alimentando así la pretensión de alcanzar la categoría de verdad incuestionable para quienes así lo han internalizado" (2003: 51).

En nuestra opinión, diremos para concluir, es así que debemos recordar que el discurso de la prensa se entiende como un dispositivo que materializa el imaginario social en el entramado de relaciones sociales y, además, "si consideramos el discurso «como el fluir del conocimiento - y de todo el conocimiento societal acumulado - a lo largo de toda la historia», [entonces se entiende la relevancia del término fluir en el sentido de la acción que] determina los hechos individuales o colectivos, así como la acción formativa que moldea la sociedad y que, de este modo, ejerce el poder. [Por consiguiente], los discursos pueden comprenderse como realidades sui generis (Jäger, 2003: 63).

\subsection{LA CRÍTICA LITERARIA PERIODÍSTICA EN CHILE: ALGUNAS IDEAS PARA SU DISCUSIÓN}

La crítica literaria constituye un dispositivo discursivo de larga tradición en Chile. Ha estado presente desde la fundación del sistema mediático, constituyendo un dispositivo que contribuyó decisivamente en la construcción del espacio público. En esta medida, emprender un análisis de la CLP no sólo es necesario, sino fundamental para la comprensión de los procesos de lucha por la hegemonía desde el siglo XIX en adelante (Nitrihual, 2007, 2009 y 2010; Nitrihual y Mayorga, 2011).

Una primera sentencia con respecto a la crítica literaria chilena es que esta nació, al igual que crítica europea (Eagleton, 1999), como un espacio de lucha contra el absolutismo. Surge como un espacio de lucha contra el ancien regime español y, posteriormente, como un espacio de discusión política, moral y religioso durante todo el siglo XX.

Ahora bien, la crítica literaria ha evolucionado junto con la industria de los medios de comunicación y de la industria literaria. Ya en el siglo XVI comienza una decadencia del mecenazgo literario y una constante y poderosa formación de libreros. Esto va de la mano del desarrollo tecnológico de la imprenta y edición, los avances educativos y la expansión de una masa lectora. A nivel general, tres fenómenos 
propios de la sociedad moderna entran en juego en la producción de crítica literaria en los medios de prensa:

a) En el plano estrictamente literario, la formación de un crítico especialista o profesional produce de manera creciente una búsqueda de personalidad y estilo en los críticos. Este culto al estilo es una búsqueda individualista al reconocimiento de un crítico que se transforma en un conocedor obsesivo de la creciente cantidad de libros que se producen. Como ha destacado, entre otros, Sloterdijk (2002: 32): en una sociedad donde la lucha por el reconocimiento es una acción primordial, el desprecio alcanza cotas endémicas. De modo que no extrañará que muchos críticos se enfrenten entre ellos por el reconocimiento de su labor.

b) Vinculado a lo anterior, los factores políticos y económicos salen a relucir en la producción de crítica. Políticamente, dado que en toda sociedad existe una lucha por asirse del control del discurso, la crítica literaria transitará hacia una fuerte politización y dogmatismo. En este sentido, las publicaciones de crítica literaria en el siglo XIX se caracterizan por tener un tono jurídico, ya no son un ámbito de consenso sino el lugar de enfrentamiento de la lucha de clases. Bajo estas presiones, la esfera pública se deforma.

c) Desde el punto de vista económico, la esfera pública es invadida por la agresividad del mercado. El paso que ha señalado Terry Eagleton (1999) del mecenazgo a los libreros y luego a las editoriales hacen que en la creación de una obra el público masivo emerja como una fuerza violenta en la que el crítico hace las veces de receptor mediador y como diría Bustamante (2003) se constituya en el "banquero simbólico" de la industria editorial.

Ahora bien, de manera más contingente en el caso chileno, en la década de 1960, la crítica literaria dejó de ser ejercicio sólo de unos pocos representantes oficiales de periódicos y se abrió a diversas instancias de producción cultural. Las universidades fueron el eje fundamental de esta actividad en la difusión del bagaje teórico analítico de las últimas décadas de la crítica europea. A partir de la reforma universitaria: "se constituye en un espacio dinamizador de persuasiones ideológicas en torno al cambio, espacio que tensiona, por lo tanto, a las distintas disciplinas respecto a su rol en un proyecto de transformación de la sociedad" (Subercaseaux, 1991: 121).

En este sentido, Subercaseaux sostiene que la modernización de la crítica es un proceso orientado a elevar la sistematicidad y rigor de los estudios de literatura que a través de la unión con otras disciplinas busca sumar elementos teóricos y un paradigma de cientificidad. Así entonces, es posible distinguir dos etapas paralelas: "en la primera predominan las corrientes que suponen una radical autonomía del fenómeno literario y que por lo tanto privilegian el texto como el único horizonte legítimo de la crítica (...). En una segunda etapa, empiezan a revelarse corrientes afines a una comprensión contextualizadora. (...) Se percibe además una utilización más ecléctica de las corrientes europeas, un esfuerzo por ajustar creadoramente a la situación nacional y latinoamericana enfoques y categorías pensados en otros contextos" (Subercaseaux, 1991: 121).

La crítica es considerada culturológica y prospectiva. Géneros nunca antes analizados son considerados objetos de estudio: el testimonio, la literatura popular y la subliteratura. De esta manera los críticos desarrollan un discurso sobre su propia 
política cultural. Incluso, podemos evidenciar que la gestación del nuevo orden cultural iniciado en la década de 1930 y con una clara participación del Estado, estaba adscrita a un objetivo de carácter inclusivo y que buscaba incorporar a los grupos desplazados como agentes activos de su propia cultura para confluir en una identidad nacional. Los beneficiados directos con esta matriz reivindicativa de la cultura chilena fueron intelectuales, críticos y artistas quienes tuvieron, por ejemplo, la posibilidad de estudiar gratuitamente.

A partir de 1973 la crítica sufrió drásticos cambios, sin embargo, lo más importante es no considerar estos cambios como un fenómeno aislado, sino como parte de las transformaciones globales ocurridas durante el periodo de la dictadura en Chile, donde el objetivo estaba focalizado, según Subercaseaux (1991: 132), en "fundar un nuevo orden social, un orden que asegure -en una perspectiva de largo aliento- la subsistencia y dominación del capitalismo en Chile". En el caso de la crítica las variables estructurales responsables de las transformaciones fueron tres:

1. Marginación cultural: corresponde a la exclusión de la vida pública de importantes sectores y la desarticulación de espacios sociales generando estrechamiento e inhibición del universo ideológico-cultural. Acarrea en la universidad tradicional la involución y neutralización del pensamiento crítico. En la "universidad informal", resultado de esta política, se produce una reflexión alternativa que aunque crece y se desarrolla, por estar acosada desde varios ángulos, encuentra grandes dificultades para alcanzar una proyección significativa.

2. Mantención de un espacio público administrado: Sólo un pequeño grupo puede incursionar en ciertos tópicos y existe un control de los temas con el propósito de lograr una integración política de la sociedad, un control que busca hacer aparecer como verdades universales las que no son sino interpretaciones afines al bloque autoritario, por supuesto, el objetivo es lograrlo de manera encubierta, como un no-control.

3. Mercantilización de lo artístico-comunicativo: El mercado es no sólo la piedra angular del modelo autoritario, sino uno de sus principales mecanismo de regulación social y cultural. Por su intermedio y en función del consumo, una gran cantidad de individuos definen sus estrategias de vida, sus gustos y hasta sus líneas de creatividad. El mundo crítico y literario empieza a ser afectado y a tener una relación de dependencia con respecto a los medios de comunicación y a la tríada de "rating-publicidad-consumo" que los alimenta, la crítica se ve cercenada en sus posibilidades teóricas o en su papel orientador. La estatura del crítico empieza a ser medida por la demanda, por su éxito en el mercado, y por lo tanto, él mismo se convierte en un producto del mercado.

\section{ASPECTOS METODOLÓGICOS DEL TRABAJO}

\subsection{CORPUS DE ANÁLISIS}

Así entonces, nos hemos propuesto describir el imaginario social de la Mujer en la crítica literaria de la Revista de Libros del diario El Mercurio entre los años 20022003. Para cumplir con lo propuesto, se ha determinado analizar un corpus confor- 
mado por las críticas literarias publicadas en la Revista de Libros del diario El Mercurio entre los años 2002-2003 y que corresponden a la difusión y juicios por parte de un crítico literario del mencionado medio de comunicación acerca de obras literarias escritas por mujeres.

\subsection{CRITERIOS DE SELECCIÓN DEL CORPUS}

\begin{tabular}{|l|l|}
\hline 1. Tipo de discurso & Crítica literaria $^{10}$. \\
\hline 2. Tipo de género & $\begin{array}{l}\text { Toda crítica literaria periodística que analiza una(s) obra(s) de } \\
\text { una(s) escritora(s). }\end{array}$ \\
\hline $\begin{array}{l}\text { 3. Tipo de medio de } \\
\text { comunicación }\end{array}$ & $\begin{array}{l}\text { Todas las críticas literarias periodísticas publicadas en medios de } \\
\text { prensa escrita (diarios). }\end{array}$ \\
\hline $\begin{array}{l}\text { 4. Identificación del } \\
\text { medio de prensa escrita }\end{array}$ & $\begin{array}{l}\text { Todas las críticas literarias periodísticas publicadas por el diario } \\
\text { El Mercurio, específicamente en el suplemento de la "Revista de } \\
\text { Libros". }\end{array}$ \\
\hline $\begin{array}{l}\text { 5. Identificación de la } \\
\text { sección del medio de } \\
\text { prensa escrita }\end{array}$ & $\begin{array}{l}\text { Todas las críticas literarias periodísticas publicadas por el diario } \\
\text { la Mercurio, específicamente en las portadas del suplemento de } \\
\text { la "Revista de Libros". }\end{array}$ \\
\hline 6. Temporalidad & $\begin{array}{l}\text { Todas las críticas literarias periodísticas publicadas en las porta- } \\
\text { das de la Revista de Libros del diario El Mercurio entre los años } \\
\text { 2002-2003. }\end{array}$ \\
\hline
\end{tabular}

\subsection{DESCRIPCIÓN DEL MÉTODO DE ANÁLISIS}

Por su parte y con la finalidad de dar cumplimiento al objetivo de nuestro trabajo, hemos elaborado un modelo de análisis del discurso sobre la base de un enfoque socio-crítico y que es empleada particularmente para el análisis de discursos mediáticos y políticos; lo que nos permitirá establecer la presencia de tópico(s), figuras, valores temáticos, posiciones de poder, modos de objetivación e implicaturas que sustentan la lógica de la crítica literaria periodística publicada en la Revista de Libros del diario El Mercurio entre los años 2002-2003.

\footnotetext{
${ }^{10}$ Dentro del tipo de discurso seleccionado como corpus de análisis, se excluyen las entrevistas, reseñas breves, ranking de libros y reportajes.
} 


\subsection{JUSTIFICACIÓN DEL MÉTODO DE ANÁLISIS}

En este sentido, el modelo de análisis propuesto nos permite estudiar -en generalel discurso mediático y -en particular- el discurso mediático de la CLP, con la intención de describir el imaginario social construido por este dispositivo mediático adscrito a una lógica comercial de un colectivo institucional como es el caso del Grupo Edwards y su diario "El Mercurio". Así entonces, se establecen un conjunto de categorías de análisis afines con la intención de determinar aquellos elementos discursivos y las relaciones de significación que sustentan los constructos de sentido acerca del imaginario social de la mujer en el marco de la producción discursiva contemporánea.

\subsection{MODALIDAD DE ANÁLISIS DEL CORPUS}

Si las construcciones socioimaginarias están sustentadas en un conjunto de principios ideológicos que logran unificar el sentido de un discurso, entonces se hace evidente la facultad que posee la configuración discursiva para categorizar, resemantizar, articular y disponer de una construcción social en torno a un colectivo, sujeto u objeto sobre la base de creencias compartidas socioculturalmente $y$, de esta manera, se establece un discurso verosímil capaz de reforzar una construcción socioimaginaria que se ha cristalizado por medio de las diversas operaciones socializadoras de cada comunidad.

Finalmente, en virtud del objetivo de la presente investigación se utilizó un modelo de análisis del discurso que se constituye a partir de los siguientes elementos:

\begin{tabular}{|l|l|}
\hline Categorías de análisis & Descripción de la categoría de análisis \\
\hline Tópico(s) & $\begin{array}{l}\text { Es el tema que engloba el sentido de un discurso o parte de él y que, } \\
\text { a su vez, posee una lógica interna en relación al contexto. }\end{array}$ \\
\hline Figuras / Rol & $\begin{array}{l}\text { Consiste en identificar las distintas figuras (actores, instituciones, } \\
\text { tiempo(s), lugar(es)), que aparecen en el discurso y el papel que se } \\
\text { les asigna a cada uno en el relato. }\end{array}$ \\
\hline Valores Temáticos & $\begin{array}{l}\text { Es el sentido que se construye a partir de las relaciones entre las } \\
\text { figuras y sus recorridos figurativos. Por lo tanto, las figuras tienen } \\
\text { un valor a partir de su relación con otras figuras. }\end{array}$ \\
\hline Posiciones de Poder & $\begin{array}{l}\text { Corresponde a la identificación de la posición del hablante (en el } \\
\text { discurso) en relación con un sujeto/institución/objeto existente en la } \\
\text { dinámica de la realidad social. }\end{array}$ \\
\hline
\end{tabular}




\begin{tabular}{|l|l|}
\hline Modos de objetivación & $\begin{array}{l}\text { Consiste en identificar las prácticas divisorias presentes en el dis- } \\
\text { curso. Estas prácticas se reconocen en dinámicas de oposición (por } \\
\text { ejemplo: normal / anormal) relacionadas con determinados suje- } \\
\text { to(s) / institución(es) / obje } \\
\text { to(s) existente(s) en la dinámica de la realidad social. }\end{array}$ \\
\hline Implicaturas & $\begin{array}{l}\text { Indicación implícita o tácita de algo, la idea de reconocer la impli- } \\
\text { catura es llevar de lo implícito a lo explícito. Es una inferencia. } \\
\text { También conocido como contenido latente. }\end{array}$ \\
\hline
\end{tabular}

\section{RESULTADOS DEL TRABAJO}

Para iniciar esta sección del trabajo es necesario precisar que producto del análisis realizado se estableció que el trabajo/producción que desarrollan las mujeres/autoras centrado en la creación de un producto literario y que corresponde a un tipo de acción/trabajo realizado por distintas mujeres en un área del desarrollo económico que no se vincula con las labores del hogar y -mucho menos- con la crianza de los hijos en la sociedad, ha sido invisibilizado. Por lo tanto, la capacidad que posee el discurso de la prensa desde la plataforma que entrega la CLP para omitir/invisibilizar en el espacio público mediático a la mujer en su papel de sujeto creador de una obra literaria, se entiende como un acto de violencia simbólica en la medida que la acción social ejercida desde una posición de poder discriminatoria refuerza y perpetúa el imaginario social de la mujer -específicamente en el caso de autoras chilenas- como un sujeto social con características situadas en el eje tradicional de lo valórico/moral y limitadas producto de su carácter emocional en lo concerniente a la legitimidad de su participación en el mundo del trabajo y de lo público.

Ahora bien, focalizados en el campo de la producción literaria, podemos evidenciar con notoriedad que existe - por lo menos desde el siglo XIX en adelante- una participación relevante de las mujeres en la creación literaria. Incluso, al considerar que en diversas sociedades occidentales contemporáneas donde aún se manifiesta una clara cultura patriarcal imperante, las obras literarias escritas por mujeres han sido y siguen siendo criticadas/interpretadas a través de un cristal misógino que subestima su valor. En este sentido la actual CLP, como orientadora de preferencias de acuerdo a determinados intereses económicos y culturales, cumple su misión de sostener el statu quo naturalizado por el hombre y que -de acuerdo a la visión androcéntrica imperante- refuerza la adscripción del género masculino en el espacio público y laboral/productivo y, por el contrario, mantiene al género femenino asentado en el espacio de lo privado y doméstico.

De esta manera, producto del análisis realizado al discurso de la CLP, hemos podido establecer que existe una acción de replicar un discurso que refuerza en la mujer su propia exclusión del ámbito público y cultural como algo natural e inexorable. Para hacer aún más efectivo tal adscripción significativa, el discurso de la CLP tiende a ejercer durante el periodo de tiempo analizado un apoyo y reconocimiento de determinadas obras literarias creadas por mujeres que ostentan una evi- 
dente participación en el espacio público mediático y cultural, pero a través de la creación de obras literarias que confirman la visión patriarcal en la sociedad contemporánea.

Así entonces, mediante nuestro análisis se pudo identificar en la CLP publicada en la Revista de Libros del diario El Mercurio el establecimiento de un esquema de ambivalencia sobre la figura/actor mujer sustentado en determinados valores temáticos y relaciones de significación cristalizadores de una determinada construcción socioimaginaria.

En tales términos, tenemos que la CLP publicada en la Revista de Libros del diario El Mercurio, por una parte, construye la figura/actor de las escritoras como mujeres que responden a características que -de acuerdo al modelo patriarcal- son asociadas a la femineidad tales como: sensibilidad, creatividad e imaginación. Pero, por otra, la CLP destaca a estas escritoras como portadoras de los atributos naturalmente masculinos como, por ejemplo, inteligencia, ambición, cultura y éxito profesional.

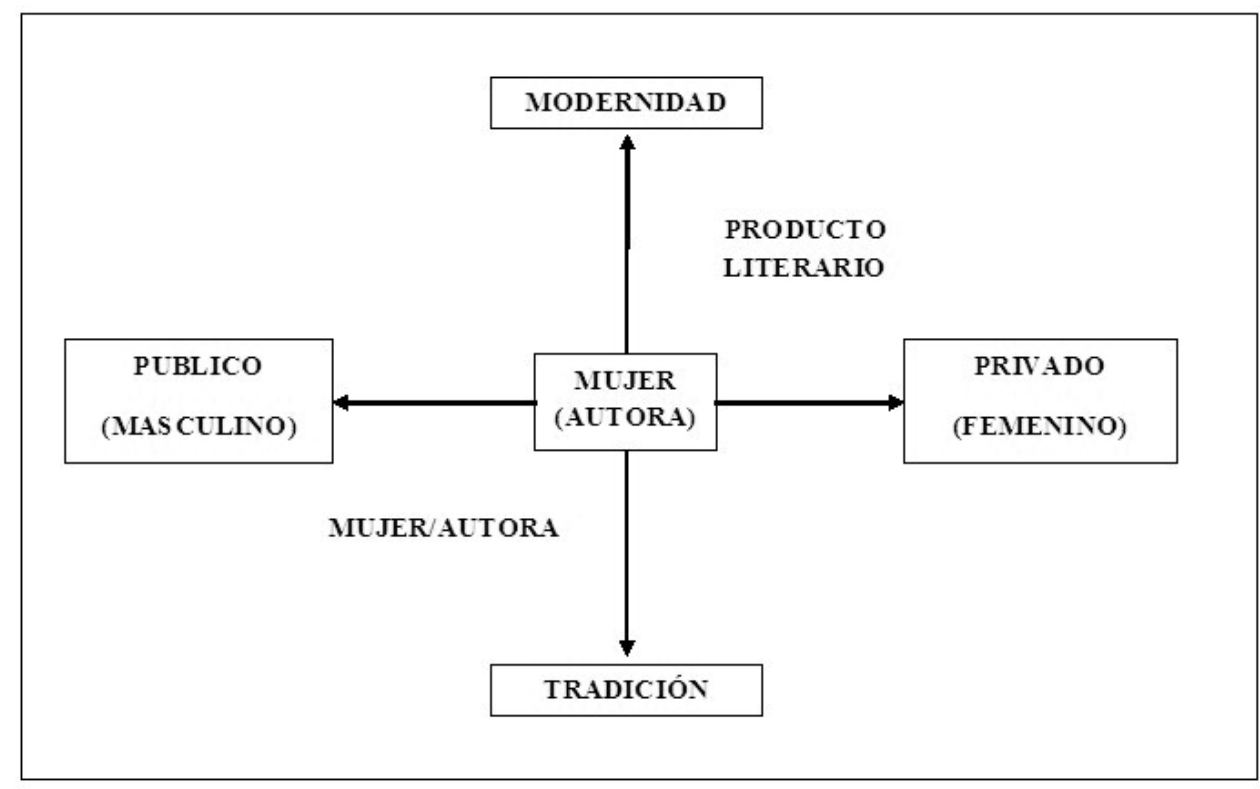

Fig. 1. Esquema de Ambivalencia. Elaboración propia a partir de los resultados obtenidos producto del análisis del discurso de la CLP

Como vemos en la Fig 1 la relación de significación que sustenta el imaginario social de la mujer a través de la producción discursiva establece que si las mujeres quieren ser visibles en el ámbito público deben ser poseedoras de las características que en términos del discurso de género representan la masculinidad. A través de esta relación de significación se mantiene la ideología en torno a la construcción social de los atributos/características de acuerdo al género determinados por los hombres. Es así como en el discurso de la CLP se invisibiliza que la mujer en su naturaleza 
sea poseedora intrínseca del profesionalismo, la independencia, el poder y otras características asociadas a los hombres.

Finalmente, si consideramos las posiciones de poder y los elementos de significación descritos en el presente estudio, es posible explicitar una disposición a establecer dos categorías de mujeres/escritoras sobre la base de su nacionalidad respectiva, es decir, en la CLP analizada existe una clara diferenciación entre las autoras nacionales y las autoras extranjeras, particularmente europeas. Las escritoras nacionales son construidas como mujeres tradicionales y conservadoras, pues su obra es un reflejo del modelo patriarcal, no obstante en el caso de las escritoras extranjeras se produce una construcción social de dichas figuras/actor asentada sobre la relación de significación de mujeres liberales y modernas conforme a la descripción y detalle narrativo de la vida que decidieron llevar y que se transforma en la materia prima para la inspiración y, posterior, producción de obras literarias relevantes para las lógicas de la producción, circulación y consumo en el mercado de la industria cultural.

\subsection{ASPECTOS DEL DISCURSO DE LA CLP SOBRE LA MUJER: PATRIAR- CADOS, TRADICIONES, MASCULINIDAD Y MODERNIDAD.}

Como parte de los resultados de nuestro análisis debemos señalar que en el caso de las autoras chilenas no son ellas el foco principal de la crítica. El eje central de la crítica es el trabajo literario que ellas han sido capaces de producir.

Las obras de las escritoras chilenas están ambientadas en nuestro país y reflejan la cultura patriarcal dominante aunque no corresponden a obras históricas. Es así como la CLP sobre las mujeres chilenas es utilizada para el refuerzo de un modelo cultural patriarcal, en donde la falta de información acerca de la vida de las escritoras y la narración de este tipo de obras nos lleva a asumir que ellas, en su propia vida, corresponden al imaginario social de mujer desarrollado por la visión androcéntrica.

De acuerdo a lo mencionado en el desarrollo teórico de nuestro trabajo acerca del carácter comercial de la CLP en Chile, podemos asumir que la elección de estas escritoras y sus obras se basa en la intención de mantener el imaginario social de la mujer relegada a lo privado y de esta manera fortalecer un mapa ideológico que los grupos de poder se empeñan en reforzar a través del discurso de la prensa.

Por su parte, en relación a las autoras extranjeras sostenemos que el eje de la CLP se centra en la descripción en detalle de la vida que cada una de las autoras destacadas en el discurso de la prensa ha construido durante un periodo de tiempo. Por tanto, el relato de los críticos se focaliza en la acción de resaltan los detalles de sus historias de vida donde estas mujeres que a pesar de su existencia en épocas distintas encajan perfectamente en el estereotipo de la mujer moderna: Mujeres independientes e inteligentes sin la pérdida de la sensibilidad característica de lo femenino.

En definitiva, la posición de poder que logramos evidenciar en el discurso de la CLP se sustenta en la diferenciación entre las mujeres/autoras chilenas y extranjeras, es decir, en el caso de las mujeres/escritoras chilenas el eje de lo tradicional y lo conservador determina su construcción socioimaginaria, por el contrario las mujeres/escritoras nacidas en Europa o criadas con influencia europea pueden des- 
arrollar características asociadas a la naturaleza masculina y, por lo tanto, el eje de la modernidad determina su construcción socioimaginaria en la medida que se relaciona de forma directa con el factor de la masculinidad vivenciada por este tipo de mujer/escritora pero siempre dentro de los límites aceptados en el ámbito de lo público.

\section{CONSIDERACIONES FINALES}

A modo general podemos concluir que el imaginario social de la mujer en la crítica literaria de la Revista de Libros del diario El Mercurio en el periodo 2002-2003, está dividido en dos ejes. El primero de estos ejes corresponde a las escritoras nacionales cuya configuración socioimaginaria está enraizada en la significación tradicional adscrita a las cualidades de sensibilidad, docilidad, etc. En tanto el segundo eje corresponde a las escritoras extranjeras configuradas socioimaginariamente desde la categoría de modernidad/vanguardia en que son representadas favorablemente como sujetos/modelos de individualidad y no como representantes de una cultura de lo propiamente femenino. En síntesis, diremos en lo esencial, que es interesante plantear y discutir acerca de la diferenciación en torno a la construcción socioimaginaria de la mujer/escritora, en la medida que de acuerdo a la cercanía o distancia con nuestra cultura se puede establecer un tipo de discurso justificador de lo moderno en el caso de la escritora extranjera y, en el caso de la escritora chilena, castigador y severo en los juicios sobre la obra y la vida de estas mujeres.

\section{REFERENCIAS BIBLIOGRÁFICAS}

Arriaga, Mercedes; Burgos, Elvira; Caballero, María; Martín, Ema; Ramírez, Carmen; VIÑUElA, Laura y VICENTE, Gemma. (2004): La mujer en la cultura y los medios de comunicación. España, Arcibel Editores.

BACZKo, Bronislaw. (2005): Los imaginarios sociales. Memorias y esperanzas colectivas. Buenos Aires, Ediciones Nueva Visión.

BAEZA, Manuel Antonio. (2000): Los caminos invisibles de la realidad social. Ensayo de sociología profunda sobre los imaginarios sociales. Santiago de Chile, RIL Editores.

BAEZA, Manuel Antonio. (2003): Imaginarios sociales. Apuntes para la discusión teórica y metodológica. Chile, Editorial Universidad de Concepción.

BAEZA, Manuel Antonio. (2008): Mundo real, mundo imaginario social. Teoría y práctica de sociología profunda. Santiago de Chile, RIL Editores.

Bustamante, Enrique. (coord.) (2003): Hacia un nuevo sistema mundial de comunicación. Las industrias culturales en la era digital. Barcelona, Gedisa.

CASTORIADIS, Cornelius. (2007): La institución imaginaria de la sociedad. Buenos Aires, Tusquets Editores.

Eagleton, Terry. (1999): La función de la crítica. Barcelona, Paidós. 
JäGER, Siegfried. (2003): "Discurso y conocimiento: Aspectos teóricos y metodológicos de la crítica del discurso y del análisis de dispositivos", en Wodak, Ruth y Meyer, Michael (ed.): Métodos de análisis crítico del discurso. Barcelona, Gedisa.

MAYORGa RoJel, Alberto Javier. (2009): "La representación del "enemigo" en el espacio público. Reflexiones en torno al concepto de discurso mediático y su relevancia en la configuración de la otredad en América Latina”, en Revista Question, Vol 1, $\mathrm{N}^{\circ} 21$, pp. 1-11.

Nitrinual, Luis, Fierro, Juan Manuel, at al. (2011): "Crítica y Literatura en José Victorino Lastarria. Ancien Regime e Ilustración" Revista Historia y Comunicación Social, Vol. 16, 2011, pp. 97-110

NitRIHUAL, Luis; MAYORGA, Alberto Javier (2011): "La crítica literaria en los orígenes del periodismo". Revista Estudios del Mensaje Periodístico n ${ }^{17}$, Vol. 1, pp. 183-194.

Nitrinual, Luis (2010): "Crítica literaria periodística, Canon, Interculturalidad". Revista de Lengua y Literatura Mapuche $\mathrm{n}^{\circ} 12-13$, 2006_2008, p. 35-47

NitrinuAL, Luis (2009): "Crítica Literaria de la Revista de Libros de El Mercurio 20022004. La construcción de un canon tradicional" Revista Significação - Revista Brasileira de Semiótica $\mathrm{N}^{\circ} 30$.

NitRinuAL, Luis (2007): "La crítica literaria de la Revista de Libros del diario chileno El Mercurio, entre los años 2002-2004". Revista Palabra Clave. Vol. 10, № 2, pp. 135-145.

NitRIHUAL, Luis (2006): "La crítica literaria de Alone y su relación con la problemática de género. Una mirada a la obra de Gabriela Mistral y Marta Brunet". Revista del Grupo de Investigación Escritoras y Escrituras, $\mathrm{n}^{\circ} 4$, en línea http://www.escritorasyescrituras.com/revista.php/4/31.

SuberCaSEAuX, Bernardo. (1991): Historia, literatura y sociedad. Ensayos de hermenéutica cultural. Santiago de Chile, CESOL.

SlOTERDIJK, Peter. (2002): El desprecio de las masas. España, Pretexto.

Thompson, John B. (1998): Los media y la modernidad. Una teoría de los medios de comunicación. Barcelona, Paidós. 


\title{
RESUMEN
}

El presente trabajo tiene por objetivo presentar los resultados de una investigación acerca de la construcción socioimaginaria de la mujer en la crítica literaria de la Revista de Libros del diario El Mercurio de Santiago de Chile en el periodo 2002-2003. De igual forma, se procederá a la descripción de algunos aspectos teóricos y conceptuales centrales del trabajo de investigación realizado con la finalidad de enriquecer el enfoque sociocrítico acerca de las relaciones de poder que ejerce la prensa en el ámbito de la producción cultural a través de la construcción de imaginarios sociales.

Palabras clave: Discurso de la prensa, imaginarios sociales, crítica literaria, poder simbólico.

\begin{abstract}
This paper presents the results of a research about the social-imaginary construction of women in the literary criticism of the Books Review section in the newspaper El Mercurio of Santiago de Chile during the period between the years 2002-2003. It contains also a description of some central theoretical and conceptual aspects of the research focused on enriching sociocritic view on relations of power exercised by the press in the field of cultural production through social imaginary construction.
\end{abstract}

Keywords: Discourse of the press, social imaginary, literary criticism, symbolic power.

\section{RÉSUMÉ}

Le présent document vise à présenter les résultats d'une enquête sur la construction socio-imaginaire des femmes dans la critique littéraire du journal El Mercurio de Santiago du Chili pour la période 20022003. De même, il montre une description de certains aspects centraux théoriques et conceptuels de la recherche effectuées envisageant d'enrichir la perspective sociocritique sur les relations de pouvoir exercés par la presse dans le domaine de la production culturelle à travers la construction sociale imaginaire.

Mots clé: Discours de la presse, l'imaginaire social, la critique littéraire, la puissance symbolique. 